\title{
Políticas públicas e extensão pesqueira em Cabedelo, Paraíba
}

Public policy and fishing extension in Cabedelo, Paraíba

Politiques publiques et l'extension de pêche à Cabedelo, Paraíba

Las políticas públicas y la extensión pesquera en Cabedelo, Paraíba

\author{
Onivaldo da Rocha Mendes Filho* \\ Angelo Brás Fernandes Callou** \\ Maria Salett Tauk Santos***
}

Recebido em 2/9/2009; revisado e aprovado em 19/12/2009; aceito em 22/2/2010

\begin{abstract}
Resumo: O estudo trata de levantamento das políticas públicas desenvolvidas pela Secretaria Especial de Aquicultura e Pesca da Presidência da República (Seap/PR), no âmbito da Extensão Pesqueira, no período de 2003 a 2008, em Cabedelo, Paraíba. A partir de documentos e entrevistas com pessoas de diversos segmentos da pesca, a análise foi realizada tendo como perspectiva teórica o desenvolvimento local.

Palavras-chave : Políticas públicas. Extensão pesqueira. Desenvolvimento local.
\end{abstract}

Abstract: The study deals with the assessment of the public policies developed by the Secretaria Especial de Aquicultura e Pesca da Presidência da República (Seap/PR) in the field of Fishing Extension from 2003 to 2008 in Cabedelo, Paraíba. The evaluation was based on documents and interviews with people working in different fishery sectors. The analysis was accomplished having the local development as the main focus point.

Key-words: Public policy. Fishing extension. Local development.

Résumé: L'étude enquête sur les politiques publiques développées par la Secretaria Especial de Aquicultura e Pesca da Presidência da República (Seap/PR) dans le contexte de l'Extension de pêche, au cours de la période 20032008, à Cabedelo, Paraíba. À partir de documents et d'entretiens réalisées avec des personnes issues de divers secteurs de la pêche, l'analyse a été effectuée d'un point de vue théorique en se centrant sur le développement local. Mots-clés: Politiques publiques. Extension de pêche. Développement local.

Resumen: El estudio se ocupa del examen de las políticas públicas desarrolladas por el Secretaria Especial de Aquicultura e Pesca da Presidência da República (Seap/PR) en el ámbito de la Extensión Pesquera, en el período 2003-2008, en Cabedelo, Paraíba. A partir de los documentos y entrevistas con las personas de los diversos sectores de la pesca. El análisis fue realizado teniendo como el punto principal al desarrollo local.

Palabras clave: Políticas públicas. Extensión pesquera. Desarrollo local.

\section{Introdução}

No Brasil, pouco se tem estudado sobre as políticas públicas para o desenvolvimento do setor pesqueiro. Após a criação da Secretaria Especial de Aquicultura e Pesca da Presidência da República (Seap/PR), em 2003, vêm se estabelecendo uma série de políticas que pretendem não apenas retomar o tempo perdido, caracterizado pelo interregno entre o encerramento das atividades da Superintendência do Desenvolvimento da Pesca (Sudepe), em 1989, e a expansão da Seap/ PR no país. Essas ações pretendem, ainda, criar novas estratégias para desenvolver a pesca e a aquicultura brasileiras.
A extensão pesqueira, que do ponto de vista teórico já havia abandonado as velhas práticas de difusão de inovações, é agora chamada a repensar as estratégias de comunicação participativas que ajudem a promover o desenvolvimento local dos contextos populares desfavorecidos do setor pesqueiro (CALLOU; TAUK SANTOS, 2003). Desenvolvimento Local compreendido como um processo de aproveitamento prioritário das potencialidades socioeconômicas e culturais das populações e organizações locais, na perspectiva de emancipação social e política (FRANCO, 2001; JARA, 2001).

O desenrolar dessas políticas pelas organizações governamentais e não

\footnotetext{
* Engenheiro de Pesca pela Universidade Federal Rural de Pernambuco (UFRPE). E-mail: valdo_rocha@hotmail.com

** Professor Titular da UFRPE e Vice-coordenador do Programa de Pós-Graduação em Extensão Rural e Desenvolvimento Local (POSMEX) da UFRPE. E-mail: peixes@elogica.com.br

*** Professora Associada da UFRPE e Coordenadora do Programa de Pós-Graduação em Extensão Rural e Desenvolvimento Local (POSMEX) da UFRPE. E-mail: mstauk@terra.com.br
} 
governamentais, seus objetivos, suas metodologias, seus públicos e seu foco de ação são ainda pouco abordados do ponto de vista acadêmico, daí a importância de se estudar as políticas públicas contemporâneas e sua relação com a extensão pesqueira na perspectiva do desenvolvimento local (PRORENDA RURAL, 2003).

O propósito deste trabalho é mapear as políticas públicas para o desenvolvimento do setor pesqueiro em Cabedelo, Paraíba, a partir da criação da Seap/PR, em 2003, até 2008, e analisar a repercussão dessas políticas em segmentos envolvidos com as atividades da pesca a partir das opiniões dos pescadores e pescadoras artesanais, além de técnicos da Seap/PR/PB e da Secretaria de Pesca e Meio Ambiente de Cabedelo (SPMA).

O presente estudo faz parte de um projeto de pesquisa mais amplo - Pescando Pescadores: Políticas Públicas e Extensão Pesqueira para o Desenvolvimento Local -, financiado pelo CNPq e desenvolvido pelo Programa de Pós-Graduação em Extensão Rural e Desenvolvimento Local (Posmex), da Universidade Federal Rural de Pernambuco, em parceria com o Programa de Pós-Graduação em Serviço Social da Universidade Federal de Pernambuco. O projeto tem a finalidade de mapear as políticas públicas desenvolvidas nos Estados da Bahia, Alagoas, Pernambuco, Paraíba e Ceará. Os resultados aqui apresentados dizem respeito a Cabedelo, município cuja atividade econômico-produtiva predominante é a pesca artesanal.

O município de Cabedelo está localizado a $18 \mathrm{~km}$ de João Pessoa, capital paraibana. Encontra-se entre o estuário do Rio Paraíba, o Oceano Atlântico e a cidade de João Pessoa (GOOGLE EARTH, 2008). Além de ser uma cidade portuária, tem, naturalmente, uma vocação marítimo-pesqueira, devido a sua localização, com logística privilegiada para o desenvolvimento da pesca em função de empresas de armazenagem e facilidade do escoamento da produção, tanto pela rodovia federal BR-230, ou pela linha férrea, quanto pelo aeroporto mais próximo, que está a $37 \mathrm{~km}$ de distância.

Cabedelo conta com 2.724 pescadores e 1.343 pescadoras que vivem quase exclusivamente da atividade pesqueira artesanal, segundo dados coletados por esta pesquisa na Colônia Z-2 desse município. Tendo em vista a importância da pesca na região, Cabedelo é favorecida com o maior número de projetos, na Paraíba, do Governo Federal, por meio da Seap/PR e da SPMA (PARAÍBA, 2008).

Para o mapeamento das políticas públicas existentes para o desenvolvimento da pesca em Cabedelo foram realizados levantamentos de dados na Seap/PB, na Secretaria de Pesca e Meio Ambiente do município (SPMA) e na Colônia de Pescadores Z-2, Presidente Epitácio Pessoa. Também foram levantadas as opiniões dos pescadores sobre as políticas públicas desenvolvidas em Cabedelo, bem como as reivindicações às instituições governamentais no período em questão, por meio de documentos e entrevistas com pessoas participantes dos movimentos sociais na pesca. Foram realizadas doze entrevistas com pescadores e pescadoras artesanais e pescadores profissionais industriais e duas com técnicos, um da Seap/PB e outro da SPMA. As entrevistas variavam de acordo com a abordagem do tema e o entrevistado. Aos pescadores foi indagado sobre a atuação das políticas públicas e como estas os beneficiavam. Já para os técnicos da Seap/PB e da SPMA foi perguntado como está o andamento dessas políticas públicas na região.

\section{Principais Políticas Públicas de Pesca Desenvolvidas em Cabedelo, 2003-2008}

\section{a) Construção do Terminal Pesqueiro Pú- blico de Cabedelo}

De acordo com o Decreto n. 5.231, de 6 de outubro de 2004, compete à Seap/PR criar, implementar, organizar, administrar, fiscalizar e apoiar os Terminais Pesqueiros Públicos. Segundo o artigo $4^{\circ}$, desse decreto, o

Terminal Pesqueiro Público é a estrutura física construída e aparelhada para atender às necessidades das atividades de movimentação e armazenagem de pescado e de mercadorias relacionadas à pesca, podendo ser dotado de estruturas de entreposto de comercialização de pescado, de unidades de beneficiamento de pescado e de apoio à navegação de embarcações pesqueiras.

Para a administração dos Terminais Pesqueiros está prevista a criação de um 
Conselho do Terminal Pesqueiro (CTP) como órgão de consulta de decisões do secretário da Seap/PR que será integrado por um representante de cada um dos seguintes órgãos: Seap/PR, Ministério do Desenvolvimento Social (MDS), Ministério do Trabalho e Emprego (MTE), Ministério da Agricultura, Pecuária e Abastecimento (Mapa), Ministério do Meio Ambiente (MMA), Estado, Município, Administração do Terminal Pesqueiro Público (TPP), pescadores profissionais artesanais, pescadores profissionais industriais, armadores de pesca, empresários do setor pesqueiro e colônia de pesca (Brasil, 2004a). De acordo com a Secretaria de Pesca e Meio Ambiente, a construção do Terminal Pesqueiro Público de Cabedelo, desenvolvida em parceria com a Seap/PR e o Governo da Paraíba, deverá atender a toda a comunidade pesqueira, sejam eles pescadores profissionais artesanais ou pescadores profissionais industriais, garantindo a finalidade pública do empreendimento, assistência técnica e incubação de empreendimentos solidários, como mecanismos de suporte à administração para que o Terminal possa ser autogerido (CABEDELO, 2008).

O Terminal Pesqueiro Público de Cabedelo está sendo construído ao lado do Porto de Cabedelo, local estratégico, tendo em vista o compartilhamento do maquinário do próprio porto, como os guinchos, por exemplo. A obra teve início em 12/7/2006, e tinha como previsão para o seu término o prazo de um ano. O valor do investimento do terminal foi de $\mathrm{R} \$ 6.378 .577,51$, de acordo com informação coletada no local da obra.

Considerando que o Terminal Pesqueiro Público está ainda em construção, não se observaram nas entrevistas com os pescadores maiores expectativas acerca do projeto, a não ser comentários em comum de que o terminal vai beneficiá-los de alguma forma, mas não sabem ao certo como será.

\section{b) Centro de Formação em Pesca e Cultura Marinha}

Criado em 2006, a partir de um projeto de cooperação mútua entre o Ministério da Educação (MEC) e a Seap/PR, em parceria com o Centro Federal de Educação Tecnológica da Paraíba (Cefet/PB), Governo Estadual, Governo Municipal e a Xunta Galicia, uma cooperação espanhola, o centro tem como objetivo desenvolver uma política de formação humana na área da pesca marinha e continental e aquicultura familiar que contemple planos e programas de formação e capacitação com vistas à gestão e aproveitamento dos recursos pesqueiros e aquícolas (Brasil, 2006a).

Considerando que o município de Cabedelo comporta uma quantidade muito grande de pessoas ligadas à pesca artesanal e que depende dessa atividade econômica para sobreviver, o Centro de Formação poderá contribuir para o desenvolvimento da atividade pesqueira local e aprimoramento profissional dos pescadores e pescadoras. Esse projeto, aliado à futura implantação do Curso de Engenharia de Pesca de Cabedelo, poderá ampliar o capital humano para o manejo sustentável dos recursos marinhos e aquícolas da região.

O Centro de Formação em Pesca e Cultura Marinha de Cabedelo já está em funcionamento com os cursos técnicos subsequentes em Pesca Oceânica e em Meio Ambiente, com 60 vagas, para quem já completou o ensino médio. Os cursos de extensão em Tecnologia de Pesca, Tecnologia do Pescado e Navegação contam com 60 vagas no total. São mais de 40 pescadores e pescadoras matriculados, distribuídos entre os cursos oferecidos. Mas alguns desses cursos não tiveram uma procura que justificasse o seu funcionamento. Os cursos de extensão têm duração média de três meses e todos os alunos matriculados estão cadastrados na Seap/PR e/ ou na Marinha, como pescador profissional. Assim se expressou o presidente da Colônia Z-2 de Cabedelo sobre esse projeto:

A parte de inscrição está sendo muito baixa. Não está sendo ainda muito aceito pela parte dos pescadores, por um primeiro motivo: o grau de instrução é baixíssimo [...] (Paulo Ferreira, presidente da Colônia Z-2 de Cabedelo).

Apesar de um número ainda considerado baixo de inscrições, os cursos são vistos com entusiasmo por parte dos pescadores e pescadoras matriculados. Disseram alguns deles:

Esse curso, ele é muito importante pra gente, porque a gente não sabia de muita coisa e hoje em dia a gente tá sabendo... Estou fazendo esse curso e já fiz o de Marisqueira [se refere ao Projeto Garças, que será visto em 
seguida]. Eu achei muito importante, todos dois (Udistiane Ribeiro, pescadora).

Pra mim está bom esse curso porque a gente se valoriza mais [...] Vou ver na abertura do cais se a gente é visto né, pelas autoridades. Sempre quando abrem esses cursos, eu gosto de fazer. O ruim é estar em casa sem fazer nada. Quando eu não tô no mar, tô aqui correndo atrás do meu futuro (Antônio Silva, pescador).

Tendo em vista a importância que representa o aprimoramento das habilidades profissionais dos pescadores artesanais para o desenvolvimento local da pesca em Cabedelo, foi constatada uma baixa demanda desses cursos pelos pescadores e pescadoras, apesar do entusiasmo observado entre os que participam dessa formação, levando a crer que o analfabetismo ainda é o principal entrave à participação dos pescadores nos cursos e que uma política como o Projeto Pescando Letras pode contribuir para uma maior procura às capacitações promovidas pelo centro de formação.

\section{c) Programa Pescando Letras}

No Brasil, os pescadores e aquicultores familiares integram uma das categorias de profissionais com um dos mais altos índices de analfabetismo. Cerca de 50\% deles são analfabetos e, se somarmos os analfabetos funcionais, esse número chega a $79 \%$ (BRASIL, 2005b).

Nesse sentido, o Programa Pescando Letras, uma parceria da Seap/PR e o Serviço Social da Indústria (Sesi), a partir do cenário sociocultural dos pescadores e aquicultores, procura:

Atender à necessidade urgente de alfabetização dos pescadores e pescadoras profissionais e aquicultores e aquicultoras familiares, jovens e adultos, numa perspectiva de educação continuada, tomando em consideração o contexto sociopolítico dessa população e o desafio de fortalecer a sua participação na construção de espaços democráticos (BRASIL, 2005a, p. 8).

Em Cabedelo, o Programa Pescando Letras enfrenta dificuldades, tais como aconteceram em Pernambuco (CARVALHO; CALLOU, 2008), a julgar pelas observações do presidente da Colônia Z-2:

Teve já três turmas aqui na área de Cabedelo,... esse resultado, a maioria dos pescadores, eles não têm como deixar a ativida- de e vir pra uma sala de aula, porque o custo mensal da família pra abranger isso daí, o governo tinha pelo menos que dar uma bolsa completa,... ela vem pela metade (Paulo Ferreira, presidente da Colônia Z-2 de Cabedelo).

De acordo com o presidente da Colônia Z-2, os cursos de alfabetização para jovens e adultos pescadores deveriam ser realizados concomitantemente com seus horários vagos de pescaria, como foram pensados originalmente, pois eles não podem parar de trabalhar para se dedicar ao estudo. A maioria dessas famílias depende exclusivamente da pesca para sobreviver.

\section{d) Projeto Garças}

A idealização do projeto surgiu a partir da comparação entre as mulheres catadoras de marisco e as garças. Ambas coletam mariscos para a sobrevivência da família. Criado em 2003, numa parceria da Seap/PB e Banco do Brasil, o projeto se propõe a construir unidades de beneficiamento de moluscos para capacitação de marisqueiras e pescadores artesanais (PARAÍBA, 2008). Assim se expressa o secretário adjunto do SPMA:

O Projeto Garças vem desde 2003... ele surgiu da necessidade dessas comunidades ribeirinhas que trabalham com o marisco... e essa extração de marisco tem uma demanda em torno de 3 toneladas de marisco vivo/ dia...e a forma de manipular esse marisco é que tava preocupando... é trabalhado a qualidade dele de forma superartesanal (Alberto Motta, secretário adjunto de Pesca e Meio Ambiente de Cabedelo).

A quantidade de resíduos provenientes do beneficiamento dos mariscos, diz ainda o secretário adjunto, preocupava os órgãos de controle ambiental. Viu-se a necessidade do aproveitamento das conchas dos mariscos para outros fins como, por exemplo, o artesanato e a construção civil, quando triturados e adicionados à argamassa. Por outro lado, a forma como era processado esse pescado preocupava os agentes de saúde, devido às condições precárias de higiene.

Viu-se a necessidade de cooperação. Como era um local onde as pessoas já têm uma associação de marisqueiras, aí sim o Governo Municipal, através da Secretaria de Pesca... começou com esse trabalho... (Alberto Motta, secretário adjunto de Pesca e Meio Ambiente de Cabedelo). 
De acordo com a Secretaria de Pesca e Meio Ambiente de Cabedelo, o projeto está sendo bem-sucedido na Associação de Marisqueiras. Mas, segundo o presidente da Colônia Z-2, o trabalho não está acontecendo como deveria. Diz ele:

Esse Projeto Garças foi implantado no Renascer, dentro da área de Cabedelo, [...] e ele tem até dezembro (2008) pra ser concluído. Caso contrário, o projeto vai ser extinto. É um projeto que abrange a área de marisco, é uma área de estuário, uma área da classe mais baixa da pesca do Brasil (Paulo Ferreira, presidente da Colônia Z-2 de Cabedelo).

\section{e) Ampliação do Subsídio ao Óleo Diesel}

Executado pela Seap, por meio de acordo com o Governo Estadual e a Petrobras, isenta pescadores e empresários da pesca da cobrança de ICMS. O objetivo é equiparar o preço do óleo nacional ao internacional (Brasil, 2006c). Segundo a Seap, o sistema eletrônico de abastecimento da Petrobras está em fase de implantação (Paraíba, 2008).

De acordo com o presidente da Colônia Z-2, o subsídio para o óleo diesel está em tramitação como projeto de lei. Diz ele:

É complicado, porque são 93 embarcações que têm direito na Paraíba, e aqui tinha um problema seriíssimo do ICMS, [...]. E o Governo do Estado deu uma isenção do ICMS, só que aqui na Paraíba é o único Estado do Brasil, em que é cobrado o IPVA de embarcações, e ele, ao invés de dar a isenção, mandou pra projeto de lei na Assembléia. Enquanto que na Assembléia não aprovar é quase impossível vir outro subsídio de óleo diesel pra cá (Paulo Ferreira, presidente da Colônia Z2 de Cabedelo).

Apesar de o subsídio ao óleo diesel não estar funcionando para as embarcações de Cabedelo, muito se espera com o funcionamento do Terminal Pesqueiro Público de Cabedelo. Segundo o secretário adjunto da SPMA, o terminal suprirá também essa política do óleo diesel.

\section{f) Recifes Artificiais Marinhos: Mecanis- mos de Exclusão de Arrasto e Recruta- mento de Lagosta}

Este projeto, a ser implantado pela Seap/PR, tem como principal proposta lançar blocos de concreto, atuando tanto como Dispositivos de Exclusão de Arrasto (DEA), quanto como Atratores e Recrutamento de
Lagostas (RL). Sua finalidade é reproduzir habitats rochosos para o aumento de populações de espécies marinhas, especialmente a lagosta, por se tratar de uma espécie com alto valor econômico, além de dar apoio às comunidades de pescadores artesanais na proteção dos recursos naturais, fornecendo alternativas econômicas para sua subsistência através de exploração de recursos renováveis. Para o município de Cabedelo, foram destinados 400 blocos, que serão lançados em uma área próxima ao Porto de Cabedelo (Ecoplan, 2005, p. 6).

Com a incorporação dos programas de desenvolvimentos locais... implantados pela Seap, vimos a necessidade de criar na rota da lagosta esses recifes artificiais, que já é uma prática realizada pelos pescadores (Alberto Motta, secretário adjunto de Pesca e Meio Ambiente de Cabedelo).

Existe uma visão clara de Desenvolvimento Local por parte da Secretaria de Pesca e Meio Ambiente de Cabedelo - PB, porém esse projeto de recifes artificiais está dependendo de outros órgãos do Governo, como, por exemplo, o Instituto Brasileiro do Meio Ambiente e Recursos Naturais Renováveis (Ibama). Como se percebe no seguinte comentário:

Foi construído... só que, no desenvolvimento do projeto, foi emperrado na hora de fazer a colocação... Que a tecnológica já existe, a necessidade de implantação está aí, local. Falta vontade política nacional, através de órgãos, que não a Seap [...]. (Alberto Motta, secretário adjunto de Pesca e Meio Ambiente de Cabedelo).

É bem visível o descaso com os materiais (Recifes Artificiais) cedidos pelo Governo Federal, uma vez que eles se encontram entulhados nas instalações do Terminal Público Pesqueiro de Cabedelo. Comenta, ainda, o presidente da Colônia Z-2:

Esses atratores não foram lançados ao mar porque o Ibama e o órgão de meio ambiente da Paraíba não permitiram esse lançamento dos blocos no mar. Apesar desses atratores serem feitos com cimento marítimo, não poluente e totalmente ambiental [...] é um berçário só pra povoamento de lagosta (Paulo Ferreira, presidente da Colônia Z-2 de Cabedelo).

Provavelmente, a implantação dos recifes artificiais, de acordo com o projeto técni- 
co proposto para recrutamento de lagostas, incrementaria sua produção na região, onde sua pesca já foi responsável pelo sustento de muitos pescadores locais. E poderia inibir a captura desses crustáceos nas épocas de defeso da espécie, principalmente com aparelhos compressores, apesar da proibição dessa prática.

\section{g) Programa Nacional de Financiamento da Ampliação e Modernização da Frota Pesqueira (Profrota Pesqueira)}

O plano surgiu a partir de um convênio entre a Seap/PR, o Banco do Nordeste e o Banco do Brasil, abrindo linhas de crédito para financiamento de petrechos e itens de custeio, até a construção e reforma de embarcações (Brasil, 2005d).

Apesar das políticas públicas empregadas para o setor Pesqueiro em Cabedelo, pouco se observa no dia-a-dia dos pescadores, que os tenha beneficiado. De acordo com entrevistas realizadas com a comunidade, um dos principais problemas enfrentados é a dificuldade de acesso ao crédito e a quitação de dívidas com os bancos.

OProfrota me preocupa pela política pesqueira... se você tem uma frota muito grande, ou você cria ou disponibiliza isso pra o grande capital, você tá negando toda visão do coletivo anterior de captura com sustentabilidade (Alberto Motta, secretário adjunto de Pesca e Meio Ambiente de Cabedelo).

No comentário acima, a linha de financiamento entra em xeque com o termo sustentabilidade, ou seja, há um questionamento sobre o aumento e a modernização da frota pesqueira, e quais consequências isso pode ter no ambiente. O secretário adjunto de Pesca e Meio Ambiente completa:

Se eu aumento a frota, vou aumentar o meu esforço de captura, e aumentando o meu esforço de captura, vai diminuir a quantidade de cotas pescadas por embarcação. E se eu faço embarcações para uma estrutura coletiva, aí sim, o coletivo vai ganhar, o ambiente ganha, e a gente não precisa ter um esforço muito grande na questão da captura (Alberto Motta, secretário adjunto de Pesca e Meio Ambiente de Cabedelo).

Segundo o secretário adjunto, o investimento em unidades de produção aquícola é, sem dúvida, o melhor caminho para a sustentabilidade do ambiente, além de uma maior inclusão social dos pescadores.

\section{h) Projeto: Apoio à Cadeia Produtiva do} Pescado Proveniente da Pesca Artesanal

Dirigido à pesca artesanal, e com o apoio da Seap/PR e do Ministério do Trabalho e Emprego (MTE), beneficia, com a implantação de fábricas de gelo, cooperativas e associações de pescadores localizadas em regiões distantes dos centros de comercialização do pescado, permitindo um ganho econômico maior para os beneficiados (Paraíba, 2008).

O presente projeto prevê a instalação de 33 fábricas de gelo, com capacidade de 1 a $3 \mathrm{t}$ / dia (três toneladas de produção de gelo em escama por dia) consoante com a necessidade dos proponentes, como apoio à cadeia produtiva do pescado proveniente de comunidades pesqueiras tradicionais organizadas, sob gestão e uso das comunidades pesqueiras (Brasil, 2004b, p. 2).

De acordo com alguns pescadores, Cabedelo recebeu a verba necessária para a implantação de uma fábrica de gelo que, porém, nunca foi feita. A colônia Z-2 não queria ficar responsável por um projeto sem estudo econômico, ou sem redução tributária de algumas tarifas, como afirma:

Não temos subsídio de energia, nem o subsídio da água [...] é praticamente impossível uma fábrica de gelo, hoje (Paulo Ferreira, presidente da Colônia Z-2 de Cabedelo).

Apesar de o projeto não ter sido executado na Colônia Z-2, a implantação do Terminal Pesqueiro Público prevê, entre outras coisas, a construção de uma fábrica de gelo que beneficiará todos os pescadores (Brasil, 2004a).

\section{i) Programa Feira do Peixe}

Tem por objetivo aproximar, por meio da comercialização direta do pescado, o aquicultor familiar e o pescador artesanal do consumidor, evitando atravessadores e barateando o custo do pescado, com preços mais justos. Consiste na distribuição de equipamentos para venda do peixe vivo e peixe fresco, e conta com parcerias, como a Seap/PR e a Companhia Nacional de Abastecimento (Conab) (BRASIL, 2005c). Diz o Conape (2005, p. 2):

O Kit Peixe Vivo é composto de estrutura metálica desmontável, puçá, tanque desmontável de mil litros, soprador, balcão para manuseio, caixas isotérmicas, bombonas 
com tampa para degelo e resíduos, balança eletrônica, avental, luvas e facas. E o outro kit, para peixe fresco, é formado por estrutura metálica desmontável, balcão para exposição e manuseio, caixas isotérmicas, bombonas com tampa para degelo e resíduos, balança eletrônica, a vental, luvas e facas.

Vejamos o que diz o presidente da colônia de pescadores:

É complicado na área de marítimo; ele funciona mais nas áreas interiores... Foi implantado no Renascer um kit com uma parceria com a Emater na feira, mas mesmo assim o resultado não foi o esperado (Paulo Ferreira, presidente da Colônia Z-2 de Cabedelo).

A Associação de Pescadores e Marisqueiras de Renascer, em Cabedelo, foi beneficiada com um kit para peixe vivo, amparando 18 famílias (BRASIL, 2006b).

Os kits foram entregues à comunidade sem nenhuma assistência técnica que a auxiliasse com o objetivo geral do projeto, que é evitar os atravessadores da cadeia produtiva da pesca artesanal. Contudo, sem uma consultoria especializada para tal tarefa, principalmente o manejo do pescado vivo para comercialização, boa parte do equipamento encontra-se sucateado pela própria comunidade, ou por não lhe ser útil, ou por não se saber ao certo como proceder com todo o material acima descrito.

\section{Considerações finais}

A pesquisa evidenciou que as principais políticas públicas pesqueiras em curso no município de Cabedelo, Paraíba, não obstante o empenho da Seap/PR para o desenvolvimento da pesca, não apresentaram uma consonância no que diz respeito às parcerias entre os órgãos do governo, como o Ibama, por exemplo. O caso mais emblemático refere-se à inserção dos recifes artificiais, que seriam responsáveis pelo incremento na produção de pescado na localidade. Na prática, a falta de articulação interinstitucional, fundamental em processos de desenvolvimento local, impossibilitou que, até o momento, o projeto fosse implementado. Tal fato tem um agravante, considerando que os atratores possibilitariam a recuperação dos estoques de pescado na região.

Nessa mesma direção, apesar de uma quantidade considerável de políticas públicas para o setor pesqueiro de Cabedelo, a pesca artesanal enfrenta dificuldades, com a falta de assistência técnica especializada, seja para orientar os pescadores no manejo adequado dos recursos pesqueiros, seja para desenvolver projetos específicos de interesse dessa população. Além disso, quando pensamos em extensão pesqueira para o desenvolvimento local, há que se considerar outras atividades produtivas do lugar. A extensão pesqueira hoje está voltada para um tipo de intervenção social que abrange a pesca não apenas na sua especificidade, mas igualmente na relação do que é específico na pesca com outras atividades produtivas, no local e a partir dele. Isto significa dizer que, em se tratando de pesca para o desenvolvimento local, a extensão pesqueira assume na contemporaneidade uma dimensão mais complexa do que foi no passado, tendo em vista os desafios socioambientais e de exclusão social contemporâneos. Nesse sentido, a extensão pesqueira é chamada a mobilizar as populações desfavorecidas que vivem da pesca artesanal e da aquicultura para o enfrentamento da pobreza e da questão ambiental; articular parcerias com organizações governamentais e não governamentais; alimentar redes de comunicação com setores ligados ao conhecimento da pesca regionais, nacionais e internacionais; articular a atividade pesqueira com outros setores produtivos, no enfrentamento dos problemas locais.

No momento em que se discute no cenário internacional, e no Brasil, a depleção dos recursos pesqueiros, a extensão pesqueira para o desenvolvimento local pode se constituir, pelo conceito contemporâneo, num esforço para instaurar um processo de gestão pesqueira compartilhada. Aspecto que, ao que parece, não vem sendo contemplado pelas políticas públicas atuais para o setor pesqueiro, se considerarmos o desenrolar dessas políticas em Cabedelo, na Paraíba. Um passo importante para reconduzir tais políticas públicas está acontecendo, ainda que de forma insuficiente, por iniciativa das universidades e dos movimentos sociais. Ampliar esses conhecimentos gerados no campo da extensão pesqueira para o desenvolvimento local transformando-os em políticas públicas, eis a questão mais urgente. 


\section{Referências}

BRASIL. Casa Civil. Decreto n. 5.231, de 6 de outubro de 2004. Dispõe sobre os princípios a serem observados pela administração pública federal na criação, organização e exploração de Terminais Pesqueiros Públicos. Disponível em: <http:// www.planalto.gov.br/ccivil_03/_ato20042006/2004/ decreto/d5231.htm>. Acesso em: 20 nov. 2008a.

Ministério da Educação. Termo de Cooperação Técnica n. 02 /2006, que entre si celebram o Ministério da Educação e a Secretaria Especial de Aqüicultura e Pesca da Presidência da República, no âmbito da Política para a formação humana na área da pesca marinha, continental e aqüicultura familiar. Disponível em: $<$ http://web3.cefetcampos.br/aquicultura/seminarionacional/TCT\%2002_2006. pdf/view>. Acesso em: 12 nov. 2008 b.

.Ministério da Educação e Cultura. Programa pescando letras. Proposta pedagógica para alfabetização de pescadores e pescadoras profissionais e aquicultores e aquicultoras familiares. 2005. Disponível em: <http:/ / portal.mec.gov.br/secad/arquivos / pdf/ secad_pescandoletras.pdf>. Acesso em: 12 nov. 2008.

Presidência da República. Secretaria Especial de Aquicultura e Pesca (Seap/PR). Projeto: Apoio à Cadeia Produtiva do Pescado Proveniente da Pesca Artesanal. 2004. Disponível em: <http:// 200.198.202.145/seap/pdf / fabricadegelo_ projeto.pdf $>$. Acesso em: 12 nov. 2008.

Presidência da República. Secretaria Especial de Aquicultura e Pesca (Seap-PR). Programa Pescando letras. 2005a. Disponível em: <http:/ / 200.198.202.145/ seap/pescando/apresentacao.htm>. Acesso em: 17 nov. 2008.

Presidência da República. Secretaria Especial de Aqüicultura e Pesca (Seap- PR. Programa Feira do Peixe. 2005b. Disponível em: <http://200.198.202.145/seap/ feiradopeixe/index.htm>. Acesso em: 17 nov. 2008.

Presidência da República. Secretaria Especial de Aquicultura e Pesca (Seap-PR). Programa Nacional de Financiamento da Ampliação e Modernização da Frota Pesqueira Nacional. Programa Profrota Pesqueira. 2005c. Disponível em: <http://200.198.202.145/seap/ Novo_Profrota/html2/historico.html>. Acesso em: 24 nov. 2008.

Presidência da República. Secretaria Especial de Aquicultura e Pesca (Seap-PR). Ata de Reunião entre a Companhia Nacional de Abastecimento (Conab) e a Secretaria Especial da Aqüicultura e Pesca da Presidência da
República (Seap/PR). 2006. Disponível em: <http:// 200.198.202.145/seap/feiradopeixe/html/ 2_\%20ATA_final.pdf>. Acesso em: 12 nov. 2008.

Presidência da República. Secretaria Especial de Aquicultura e Pesca (Seap-PR). Instrução Normativa n. 18, de 25 de agosto de 2006. Altera o Programa de Subvenção Econômica ao Preço do Óleo Diesel adquirido para o abastecimento de embarcações pesqueiras nacionais e dá outras providências. Disponível em: <http://200.198.202.145/seap/html/ PARA \% 20SITE/IN\% 202006/PDFs/IN_18_Oleo\% 20diesel.pdf $>$. Acesso em: 12 nov. de 2008c.

CABEDELO (PB). Secretaria de Pesca e Meio Ambiente. Relatório: Seminário de Gestão. [Cabedelo], 20 maio 2008.

CALLOU, Angelo Brás Fernandes; TAUK SANTOS, Maria Salett. Extensão pesqueira e gestão no desenvolvimento local. In: PRORENDA RURAL. Extensão pesqueira: desafios contemporâneos. Recife: Bagaço, 2003. p. 223-236.

CARVALHO, Felipe Eduardo A.; CALLOU, Angelo Brás Fernandes. Extensão pesqueira e desenvolvimento local: a experiência da Secretaria Especial de Aquicultura e Pesca, no Estado de Pernambuco, 2003-2006. Interações, Campo Grande, v. 9, n. 1, p. 65-76, jan./jun. 2008.

CONAPE. Resoluções da $3^{a}$ Plenária do Conape: Comitê Temático Permanente n.3 - comercialização e infraestrutura. 2005. Disponível em: <http:// 200.198.202.145/seap/pdf/conape/CTP3_2.pdf>. Acesso em: 12 nov. 2008.

ECOPLAN. Plano Operacional Para a Instalação de Dispositivos de Exclusão de Arrasto e Recrutamento de Lagostas. Cabedelo (PB), 2005.

FRANCO, Augusto de. Capital social: leituras de Tocqueville, Jacobs, Putnam, Fukuyama, Maturana, Castells e Levy. Brasília: Instituto de Política, 2001.

GOOGLEEARTH. 2008. Disponível em: <http://maps. google.com/maps?1l=-7.0050604,-34.832221\&z= 12\&t=h\&hl=pt-BR>. Acesso em: 12 nov. 2008.

JARA, Carlos Julio. As dimensões intangíveis do desenvolvimento sustentável. Brasília : IICA, 2001.

PARAÍBA. Secretaria Especial de Aquicultura e Pesca. Superintendência da Paraíba (Seap-PR/ PB). Principais ações na Paraíba, 2002-2007. Lâminas cedidas pelo próprio órgão. 2008.

PRORENDA RURAL-PE. Extensão pesqueira: desafios contemporâneos. Recife: Bagaço, 2003. 